\title{
Happiness as a Measure of Mental Health - Validation of the Portuguese Version of the Oxford Happiness Questionnaire
}

Margarida Figueiredo-Braga ( $\square$ mmfb@med.up.pt )

University of Porto

Filipe Pinto

Knok healthcare UK, Ltd

José Luís Pais Ribeiro

University of Porto

\section{Research Article}

Keywords: happiness, happiness measurement, Oxford Happiness Questionnaire

Posted Date: December 20th, 2021

DOI: https://doi.org/10.21203/rs.3.rs-1085006/v1

License: (c) (1) This work is licensed under a Creative Commons Attribution 4.0 International License.

Read Full License 


\section{Abstract}

Background: Happiness is a complex concept that has been associated with mental health. Measures of happiness incorporate affective states predisposition and personality traits. Following the link established between subjective wellbeing and positive emotions and mental health, the Oxford Happiness Questionnaire (OHQ) may be considered a broad measure of personal happiness. We aimed to validate $\mathrm{OHQ}$ in the Portuguese speaking population.

METHODS: A sample of 421 young adults fulfilled the 29 and 8-item items of OHQ Portuguese version. Participants also completed the Perceived Stress Scale, Subjective Happiness Scale and the Hospital Anxiety and Depression Scale. A principal component analysis with Varimax rotation, Kaiser rule, complemented by a scree plot graphical representation, was performed.

RESULTS: Seven components of the OHQ explained $58.22 \%$ of the total variance, and a correlation of 0.90 between the long 29 items version and the 8 items short version. Both versions related inversely with negative feelings (depression, anxiety, and stress), and directly with subjective happiness.

CONCLUSION: The OHQ performs as a happiness assessment tool suitable for patients and healthy populations. The application of this questionnaire may furthermore contribute to clarify the concept of happiness and test the real usefulness of these tools in the clinical setting.

\section{Introduction}

Happiness can be defined in many different ways, but it is much more than "not being depressed". Happiness depends on the constant and consistent predisposition to face life-events with positive emotional responses, while keeping the negative emotions to a minor extent (1-3). This "predisposition to happiness" or to "experience positive emotions" had been related to a range of personality traits such as: extraversion, agreeableness, conscientiousness and openness (4-7).

Regardless of how "happiness" is defined, it has shown clinical relevance in multiple settings. It has been associated to lower suicide rates, better prognosis after cardiac events $(8,9)$, and, in a 15 years of research review of Fordyce(10), it was concluded that measures of happiness "can provide a general assessment of emotional, social, and mental health functioning".

A more recent study, including 143 nations (11), concluded that "the link between mental health and happiness is quite strong". On a more generic assessment, positive emotions were associated with better psychological health, lower suicide and depression rates (12), better physical health (13), increased longevity (14), lower incidence of strokes, higher levels of secretory IgA, and decreased levels of salivary cortisol (15).

Hills and Argyle developed the Oxford Happiness Questionnaire (OHQ) as a broad measure of personal happiness or/and to assess subjective well-being (SWB) (16).OHQ authors consider happiness as a 
manifestation of positive emotions and not a measure of discomfort, in opposition to the traditional measures of depression. The OHQ includes the same basic 29 items of a previous and parent instrument, the Oxford Happiness Inventory (OHI), but re-expressed each issue in terms of the conventional Likert-type response format (17). This inventory was originally based on the underlying hypothesis that happiness includes three partially independent components: the frequency and intensity of positive affect or joy, the average level of satisfaction, and the absence of negative feelings, such as depression and anxiety (18). Some authors have stated the OHQ decreases its utility in the study of SWB when compared with other available measures(19). Measures of SWB should be informed by theory-driven definitions of well-being, and according to them, Hills and Argyle fail to specify a definition and a theory of SWB that supports the item content of their scale (16).

The $\mathrm{OHI}$ was developed following the design of the Beck Depression Inventory (BDI) (20), including 21 $\mathrm{BDI}$ items reworded so that the item content was focused on manifestations of positive emotions, in a way that it evaluates well-being instead of discomfort. At the end, adding and removing items, it results in the present 29-item $\mathrm{OHQ}$.

In this context, the objective of the present study is to explore the validity of the Portuguese version of the $\mathrm{OHQ}$.

\section{Methods}

\section{Participants}

For the validation of the $\mathrm{OHQ}$, we recruited a convenience sample of 421 young adults, with mean age 19.42 years, $(S D=2.50$, between 17 and 36$)$ and $68.6 \%$ females.

Concurrent validation of the $\mathrm{OHQ}$ used a partial sample of 197 individuals, constituting a convenience sample, with mean age 18.18 years ( $S D=1.86$, between 17 and 35$)$ and $68.5 \%$ females.

\section{Material}

\section{Oxford Happiness Questionnaire}

Happiness was assessed by the 29-item measure Oxford Happiness Questionnaire (16) in its long and 8item short versions. The 29 items are distributed by the following dimensions: positive cognition, social commitment; positive affect, sense of control, physical fitness, satisfaction with self, mental alertness.

We developed a Portuguese translated version of the English version of the OHQ. translation was performed by two independent translators; the two translated versions were compared, discussed and, based on content analysis, the appropriate format was adopted and the final solution was back translated. Two experts inspected items for content analysis, and a focus group of young adults tested the comprehensibility of the items to define the final solution. 
According to $\mathrm{OHQ}$, each item is assessed with a six-point scale ranging from "strongly disagree" (discordo totalmente) to "strongly agree" (concordo totalmente).

Based on stepwise discriminant analysis, authors identified a smaller number of OHQ items that successfully predict group membership, and use them to propose a shorter version of the OHQ with 8 items "for use when time is limited"(16). Cruise, Lewis, \& Guckin suggested that, the shorter and simpler version may be used in place of the longer-established form(21). In the short form, three items are reversed scored. Scores range from 8 to 48 , with higher scores indicating a higher level of happiness.

For the process of validation, participants also completed the following scales:

Perceived Stress Scale (PSS): planned to measure the degree to which situations in one's life are appraised as stressful. PSS was designed to be used with community samples with at least a junior high school education. It is a self-report measure of stress with 10 unidimensional items answered in a Likert format, with five alternatives scored between 0 and 4 (Never to Very often), ranging from 0 to 40 . Higher scores in PSS indicate more stress (22). We used a Portuguese version from Pais Ribeiro and Marques (23).

Subjective Happiness Scale (SHS): is a 4-item scale of global subjective happiness. It assesses respondents' extent of agreement with self-descriptive statements, using a 7-point Likert type scale (24, 25).

Hospital Anxiety and Depression Scale (HADS): Hospital Anxiety and Depression Scale $(26,27)$ includes 14 items distributed by two subscales, one measuring anxiety (with 7 items) and one measuring depression (with 7 items), which are scored separately. Each item was answered on a 4-point (0-3) response scale, with the scores ranging from 0 to 21 for anxiety, and from 0 to 21 for depression. It takes 2-5 min to complete (Snaith, 2003). The HADS manual indicates that a score between 0 and 7 is

"normal", between 8 and 10 is "mild", between 11 and 14 is "moderate", and between 15 and 21 is "severe". An analysis of scores, on the two subscales of a further sample, in the same clinical setting, concluded that a score of $0-7$, for either subscale, could be regarded as being in the normal range.

\section{Procedures}

Participation in the study was voluntary and data confidentiality was assured. The questionnaire was delivered in paper format and completed during class-time, between 2014 and 2015.

Data were analysed using SPSS version 25.0. Following original procedure for exploratory factor analysis (EFA), we conducted a principal component analysis (PCA) with Varimax rotation, Kaiser rule, perhaps the method most utilized in PCA and EFA (28), in which only the factors with eigenvalues greater than one are retained for interpretation.

As a complement, we used also the scree plot, which displays a graphical representation of the eigenvalues associated in a descending order graph. 


\section{Results}

Kaiser Rule results found seven components explaining $58.22 \%$ of the total variance.

The inspection of the scree plot, according to Cattell's recommendations, suggested that a onecomponent solution was appropriate.

The correlation between the long 29 items version and the short 8 items version was 0.9 .

Cronbach Alpha was 0.91 for the long version (original version 0.91) and 0.70 for the reduced version (original version not reported). There were no statistically significant differences for gender and no correlation of age with all the variables in the equation. For convergent validity we inspected positive and negative correlations between measures related with happiness. The results are depicted in Table 1 .

Table 1

Correlations between measures used for convergent validity.

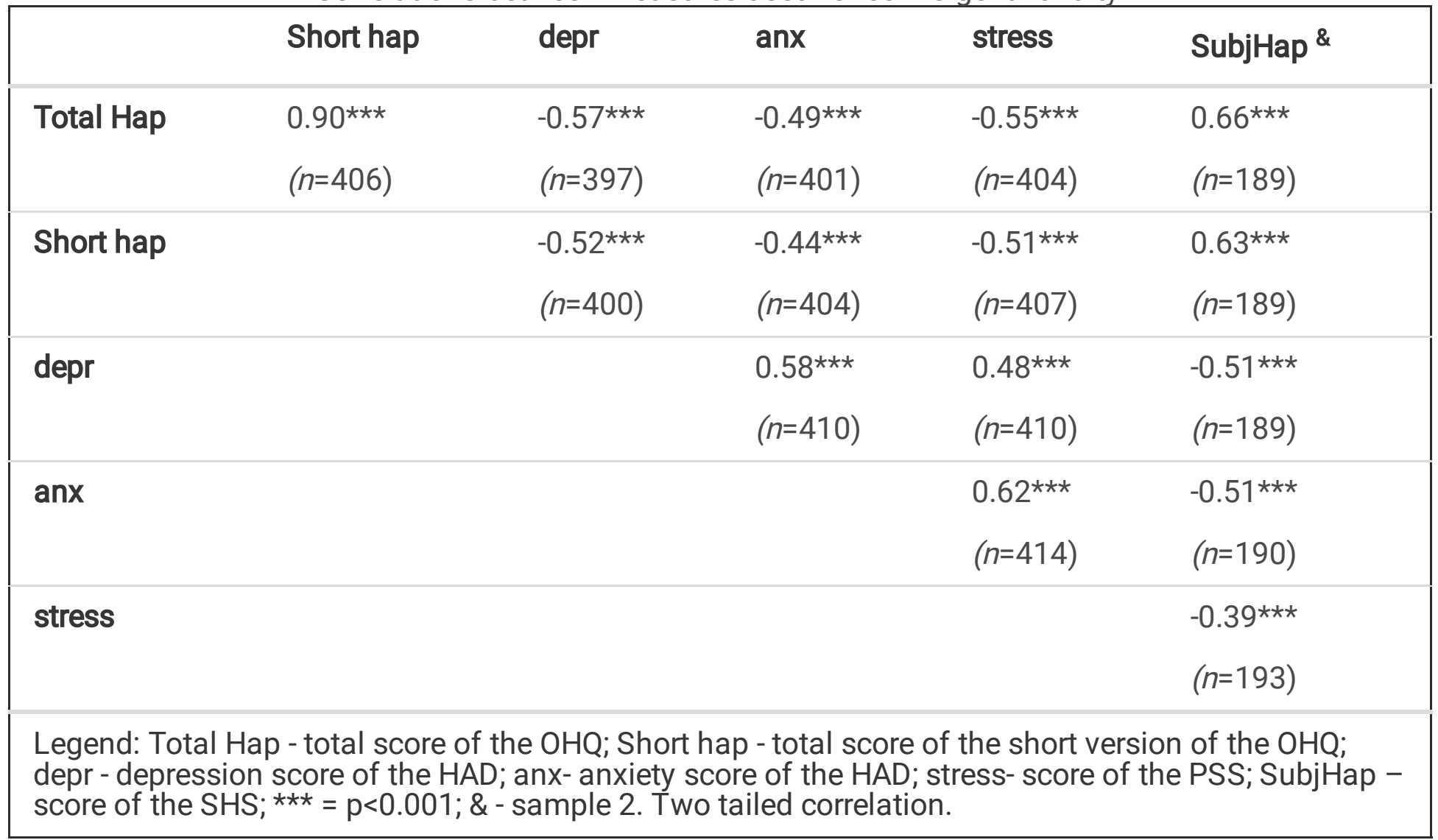

$\mathrm{OHQ}$ long and short forms correlations with anxiety and greatest with subjective happiness. We used multiple regression analysis to identify the prediction magnitude of the predictive variables (subjective happiness, anxiety, depression, and stress) on criterion variables (long and short form of OHQ). We opted for the stepwise variable selection procedure in which variables are sequentially entered into the model. 
For the $\mathrm{OHQ}$ long version, results show an adjusted $R$ square $=0.55 ; F(3.178)=189.33, p<.0001$ (using the stepwise method). Predictors are, from larger predictor to lower predictor, subjective happiness and stress, with a significance of $p<0.0001$, and depression with a significance $p<0.001$. Anxiety is not a significant predictor and was excluded from the equation.

For the $\mathrm{OHQ}$ short version, results showed an adjusted $R$ square $=0.48 ; F(3.178)=151.91, p<0.0001$ (using the stepwise method). Predictors were, from larger predictor to lower predictor, subjective happiness, and stress with a significance of $p<0.0001$, and depression with a significance of $p<0.01$. Anxiety was not a significant predictor and was excluded from the equation.

\section{Discussion}

In this study, we evaluated the validity of the Portuguese version of the OHQ and our Kaiser Rule results were similar to those of the original and other studies (64.3\% for Hills and Argyle, 2002) (16). Like in other versions, the extracted $\mathrm{OHQ}$ factors could not be plausibly interpreted. We explored alternative factorisations, but interpretability was not facilitated.

Research says that Kaiser rule shows tendency to overestimate the number of factors (29). Thus, it has been suggested that Cattell's scree test is a more reliable indicator of the number of factors to be extracted, since it draws on the relative values of the eigenvalues and is not sensitive to the number of variables in the analysis (30). The inspection of the scree plot returned similar findings to those of Hills and Argyle study in which it was concluded that "the construct of well-being measured by the OHQ can better be considered as unidimensional"(16).

The analysis of the correlation between the long 29 items version and the short 8 items version suggests that the 8 items were sufficiently correct to classify respondents' scores. The original study reports a correlation of 0.93 between long and short form. The obtained values correspond to recommendations for minimally acceptable reliability level $(31,32)$. Cruise et al reported reliabilities of 0.62 and 0.58 , in different occasions (21).

According to Cohen's recommendations $(33,34)$, the results in Table 1 show that most of correlations between $\mathrm{OHQ}$ long and short forms and the other variables are strong. In accordance with the original authors, our study shows that the OHQ (short and long versions) related inversely with negative feelings (depression, anxiety and stress), and directly with subjective happiness. Multiple regression with the long and short form, as criterion variables and depression, anxiety, stress and subjective happiness, showed that, except for anxiety, the other predictors contribute to the explanation of criterion variable ( $55 \%$ for the long version and $48 \%$ for the short version).

The long form of OHQ presents several limitations. As reported by Kashdan (19), this form appears to measure an amalgamation of dimensions, not in accordance with the theoretical models of happiness and subjective well-being, like various human strengths, cognitive characteristics, and physical fitness. However, the short form maintains some of the items that Kashdan highlights. 
Happiness and well-being have been associated to low levels of Neuroticism and high levels of Extraversion. Low levels of neuroticism were shown to be the strongest determinant to happiness rates $(35,36)$. These findings are probably related to the fact that neuroticism predisposes to negative emotions and affects $(37,38)$ which modulate one's perception of happiness and satisfaction with life.

In his review, Fordyce explained that happiness measures are valid and quick indexes of global mental health (10). The Portuguese version of the OHQ shows appropriate psychometric properties for both the long form and the short form. Correlation results suggest that the shorter and simpler version may be used in place of the longer-established form, in all situations including those when time is limited, as suggested by the original author.

In conclusion, considering the relatively low impact of sociodemographic variables in happiness, it can be hypothesized that the individual predisposition to be happy is overall mediated by personality. Happy individuals are then expected to be more resilient to unfavorable conditions, expressing less negative emotions with better physical and mental health, even in the verge of stressful events.

Previous studies in the field lead the authors to perspective happiness assessment tools as useful and feasible, both to assess psychological resilience to mental and physical disease and to shortcut personality questionnaires, which are usually very long and unpractical (39).

Using happiness assessment tools such as $\mathrm{OHQ}$, in hospital inpatient and outpatient's units, will allow further analysis of "happiness" conceptualization and test the real usefulness of these tools in the clinical setting.

\section{Declarations}

\section{Ethics approval and consent to participate}

The study was approved by the Faculty of Medicine of University of Porto and Hospital São João Ethics Committee according to the Declaration of Helsinki. Participants received written information about the study procedures and aims, and they all signed an informed consent form.

Confidentiality and anonymity were assured through codification of the collected data.

\section{Competing interests}

All authors certify that they have no affiliations with or involvement in any organization or entity with any financial interest or non-financial interest in the subject matter or materials discussed in this manuscript

\section{Consent for publication}

Not applicable 
The dataset supporting the conclusions of this article is available by request to the corresponding author.

\section{Funding}

No external funding was received.

\section{Authors' contributions}

All authors contributed to the study conception and design. Material preparation, data collection and analysis were performed by Margarida Figueiredo-Braga and José Luís Pais Ribeiro. The first draft of the manuscript was written by Filipe Pinto and José Luís Pais Ribeiro and all authors commented on previous versions of the manuscript. All authors read and approved the final manuscript.

\section{Acknowledgements}

The authors would like to thank to the medical students who accept to participate in the study. We are also thankful to Sara Rocha for data insertion.

\section{References}

1. Raibley JR. Happiness is not Well-Being. J Happiness Stud [Internet]. 2012 Dec 19;13(6):1105-29. Available from: http://link.springer.com/10.1007/s10902-011-9309-z

2. Gallagher MW, Lopez SJ, Preacher KJ. The hierarchical structure of well-being. J Pers [Internet]. 2009 Aug;77(4):1025-50. Available from: http://www.ncbi.nlm.nih.gov/pubmed/19558444

3. Haybron DM. The Pursuit of Unhappiness: The Elusive Psychology of Well-Being. Oxford University Press; 2008.

4. Haslam N, Whelan J, Bastian B. Big Five traits mediate associations between values and subjective well-being. Pers Individ Dif [Internet]. 2009 Jan;46(1):40-2. Available from: https://linkinghub.elsevier.com/retrieve/pii/S0191886908003292

5. Marrero Quevedo RJ, Carballeira Abella M. Well-being and personality: Facet-level analyses. Pers Individ Dif [Internet]. 2011 Jan;50(2):206-11. Available from: https://linkinghub.elsevier.com/retrieve/pii/S0191886910004733

6. González Gutiérrez JL, Jiménez BM, Hernández EG, Puente CP. Personality and subjective well-being: big five correlates and demographic variables. Pers Individ Dif [Internet]. 2005 May;38(7):1561-9. Available from: https://linkinghub.elsevier.com/retrieve/pii/S0191886904002958

7. Digman JM. Personality Structure: Emergence of the Five-Factor Model. Annu Rev Psychol [Internet]. 1990 Jan;41(1):417-40. Available from: https://www.annualreviews.org/doi/10.1146/annurev.ps.41.020190.002221

8. Ostir G V, Markides KS, Peek MK, Goodwin JS. The association between emotional well-being and the incidence of stroke in older adults. Psychosom Med. 2001;63(2):210-5. 
9. Middleton RA, Byrd EK. Psychosocial Factors and Hospital Readmission Status of Older Persons with Cardiovascular Disease. J Appl Rehabil Couns [Internet]. 1996 Dec 1;27(4):3-10. Available from: http://connect.springerpub.com/lookup/doi/10.1891/0047-2220.27.4.3

10. Fordyce MW. the Happiness Measures: a Sixty Second. Soc Indic Res. 1987;20(1988):373-99.

11. Touburg G, Veenhoven R. Mental Health Care and Average Happiness: Strong Effect in Developed Nations. Adm Policy Ment Heal Ment Heal Serv Res [Internet]. 2015 Jul 5;42(4):394-404. Available from: http://link.springer.com/10.1007/s10488-014-0579-8

12. Bray I, Gunnell D. Suicide rates, life satisfaction and happiness as markers for population mental health. Soc Psychiatry Psychiatr Epidemiol [Internet]. 2006 May 25;41(5):333-7. Available from: http://link.springer.com/10.1007/s00127-006-0049-z

13. Perneger T V., Hudelson PM, Bovier PA. Health and happiness in young Swiss adults. Qual Life Res [Internet]. 2004 Feb;13(1):171-8. Available from: http://link.springer.com/10.1023/B:QURE.0000015314.97546.60

14. Danner DD, Snowdon DA, Friesen W V. Positive emotions in early life and longevity: Findings from the nun study. J Pers Soc Psychol. 2001;80(5):804-13.

15. Barak Y. The immune system and happiness. Autoimmun Rev [Internet]. 2006 Oct;5(8):523-7. Available from: https://linkinghub.elsevier.com/retrieve/pii/S1568997206000279

16. Hills P, Argyle M. The Oxford Happiness Questionnaire: a compact scale for the measurement of psychological well-being. Pers Individ Dif [Internet]. 2002 Nov;33(7):1073-82. Available from: https://linkinghub.elsevier.com/retrieve/pii/S0191886901002136

17. Argyle M, Martin M, Crossland J. Happiness as a function of personality and social encounters. Recent Adv Soc Psychol An Int Perspect. 1989;189-203.

18. Argyle M, Crossland J. The dimensions of positive emotions. Br J Soc Psychol. 1987;26(2):127-37.

19. Kashdan TB. The assessment of subjective well-being (issues raised by the Oxford Happiness Questionnaire). Pers Individ Dif [Internet]. 2004 Apr;36(5):1225-32. Available from: https://linkinghub.elsevier.com/retrieve/pii/S0191886903002137

20. Beck AT, Ward CH, Mendelson M, Mock J, Erbaugh J. An Inventory for Measuring Depression. Arch Gen Psychiatry. 1961;4(6):561-71.

21. Cruise SM, Lewis CAC, Mc Guckin C, Guckin C. Internal consistency, reliability, and temporal stability of the Oxford happiness questionnaire short-form: Test-retest data over two weeks. Soc Behav Pers. 2006;34(2):123-6.

22. Cohen S, Kamarck T, Mermelstein R. A Global Measure of Perceived Stress. Vol. 24, Journal of Health and Social Behavior. 1983. p. 385-96.

23. Pais-Ribeiro J, Marques T. A Avaliação do Stresse: A propósito de um estudo de adaptação da escala de percepção de stresse. Psicol Saúde Doenças. 2009;10(2):237-48.

24. Lyubomirsky S, Lepper $\mathrm{H}$. A measure of subjective hap- piness: Preliminary reliability and construct validation. Soc Indic Res. 1999;46:137-55. 
25. Pais-Ribeiro JL. Validação transcultural da escala de felicidade subjectiva de lyubomirsky e lepper. Psicol Saúde Doenças. 2012;13(2):157-68.

26. Zigmond AS, Snaith RP. The hospital anxiety and depression scale. Acta Psychiatr Scand. 1983;67(6):361-70.

27. Pais-Ribeiro J, Silva I, Ferreira T, Martins A, Meneses R, Baltar M. Validation study of a Portuguese version of the Hospital Anxiety and Depression Scale. Psychol Health Med [Internet]. 2007 Mar;12(2):225-37. Available from: http://www.tandfonline.com/doi/abs/10.1080/13548500500524088

28. Fabrigar LR, Wegener DT, MacCallum RC, Strahan EJ. Evaluating the use of exploratory factor analysis in psychological research. Psychol Methods. 1999;4(3):272.

29. Zwick WR, Velicer WF. Comparison of five rules for determining the number of components to retain. Psychol Bull [Internet]. 1986;99(3):432-42. Available from: http://doi.apa.org/getdoi.cfm? doi $=10.1037 / 0033-2909.99 .3 .432$

30. Cattell RB. The scree test for the number of factors. Multivariate Behav Res. 1966;1(2):245-76.

31. Peterson RA. Meta-analysis of Alpha Cronbach 's Coefficient. J Consum Res. 2013;21(2):381-91.

32. Nunnally J, Bernstein I. Psychometric Theory, Series in Psychology. Vol. 2. McGraw-Hill; 1978.

33. Cohen J. A Power Primer. Psychol Bull. 1992;112(July):155-9.

34. Jacob C. Statistical Power Analysis for the Behavioral Sciences. Second. Lawrence Erlbaum Associates, Publishers; 1988.

35. Chico Librán E. Personality dimensions and subjective well-being. Span J Psychol [Internet]. 2006 May;9(1):38-44. Available from: http://www.ncbi.nlm.nih.gov/pubmed/16673621

36. Steel P, Schmidt J, Shultz J. Refining the relationship between personality and subjective well-being. Psychol Bull [Internet]. 2008 Jan;134(1):138-61. Available from: http://www.ncbi.nlm.nih.gov/pubmed/18193998

37. Costa PT, McCrae RR. Influence of extraversion and neuroticism on subjective well-being: Happy and unhappy people. J Pers Soc Psychol [Internet]. 1980;38(4):668-78. Available from: http://doi.apa.org/getdoi.cfm?doi=10.1037/0022-3514.38.4.668

38. DeNeve KM, Cooper $\mathrm{H}$. The happy personality: A meta-analysis of 137 personality traits and subjective well-being. Psychol Bull [Internet]. 1998;124(2):197-229. Available from: http://doi.apa.org/getdoi.cfm?doi=10.1037/0033-2909.124.2.197

39. Weiner, Irving B, Greene RL. Handbook of Personality Assessment. 2ND ed. Wiley; 2017. 